Cadernos de História, Belo Horizonte, v. 22, n. 37, Novembro de 2021

DOI: https://doi.org/10.5752/P.2237-8871.2021v22n37p263-279

\section{Processo de ESPORTIVIZAÇÃo DA NATAÇÃO: TEMPO, ESPAÇO E BUROCRATIZAÇÃO EM COMPETIÇÕES NO LitoRAL DE FORTALEZA (DÉCADAS DE 1920-1940)}

Nara Romero Montenegro Universidade Estadual de Campinas nararomerom@hotmail.com

\title{
Resumo
}

A natação, como modalidade esportiva, foi precedida por práticas como banhos de mar e o nado. Embora locomover-se na água fosse uma atividade que permeou inúmeras sociedades em diversos tempos históricos, a natação como prática competitiva, institucionalizada e burocratizada é uma invenção dos tempos modernos. Para Norbert Elias e Eric Dunning (1992), o processo de esportivização caracterizase pelas transformações de diversos jogos e atividades em esportes modernos, regulamentados por regras universais e escritas, além de serem sustentados por aparatos burocráticos e institucionais. No contexto brasileiro, mais especificamente no litoral da cidade de Fortaleza, a natação como modalidade esportiva, refinada por uma técnica e com intuito competitivo, viveu importante parte do processo de esportivização na primeira metade do século XX. Este artigo tem como objetivo analisar esse processo na natação no contexto do litoral cearense, entre as décadas de 1920 e 1940, evidenciando as manifestações nesse sentido, os agentes e as entidades envolvidas, bem como aspectos relativos à institucionalização do espaço litorâneo e à burocratização e racionalização da prática da natação no mar. Como fontes, foram mobilizados periódicos que circulavam na imprensa, no período e exerciam função essencial na dinâmica e desenvolvimento da prática esportiva da natação.

Palavras-chave: Natação; esporte moderno; litoral; Fortaleza.

Recebido em 23 de novembro de 2020.

Aprovado em 12 de maio de 2021. 
Cadernos de História, Belo Horizonte, v. 22, n. 37, Novembro de 2021

DOI: https://doi.org/10.5752/P.2237-8871.2021v22n37p263-279

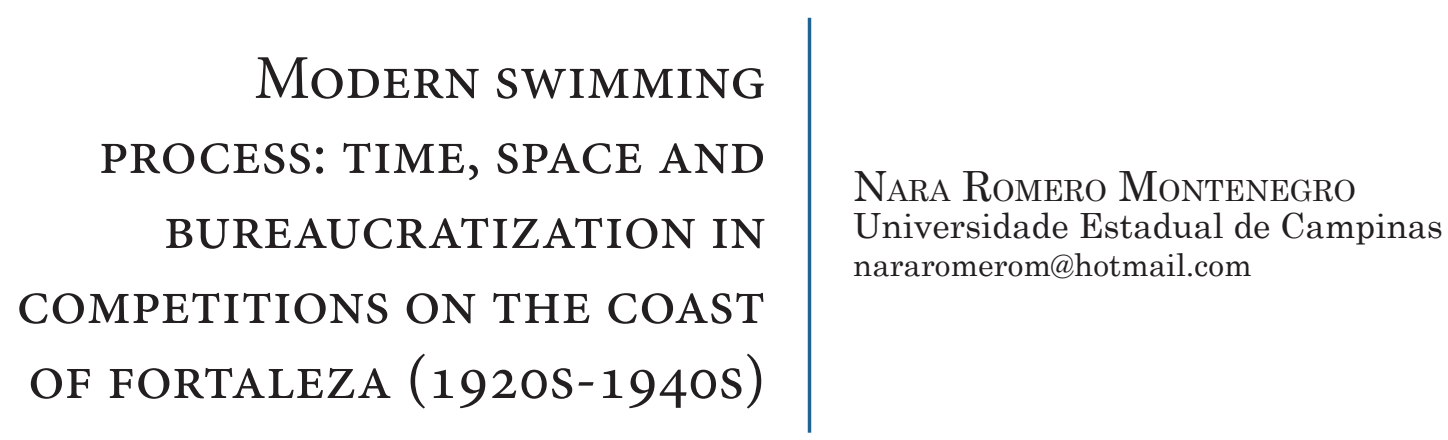

\begin{abstract}
The swimming, as a modality, was preceded by practices such as sea bathing and other types of swimming. Although moving into the water was an activity that was performed in many societies in different historical times, swimming as a competitive, institutionalized, bureaucratic practice is an achievement of modern times. According to Norbert Elias and Eric Dunning (1992), the modern sport process is characterized by the change of different games and activities into sports, regulated by universal and written rules, besides it is supported by bureaucratic and institutionalized aspects. In the Brazilian context, specifically on the coast of the city of Fortaleza, swimming as modality, supported by a technique and with a competitive aim, it experienced an important part of this process in the first half of the 20th century. This article aims to analyze this process in swimming, in the context of the Ceará coast, between the 1920s and 1940s, highlighting the manifestations in this direction, the agents and institutions involved, as well as aspects related to the institutionalization of the coast, the bureaucratization and rationalization of the swimming at sea. The sources used were periodicals that circulated in the press in that time, which played an essential role in the dynamics and development of swimming as a sport.
\end{abstract}

Keywords: Swimming; modern sport; coast; Fortaleza. 


\section{INTRODUÇÃo}

Analisar historicamente a natação, modalidade esportiva moderna, é antes entender o espaço no qual ela se inseria e as práticas que a antecederam nesses espaços. No começo do século XX, eram poucas as piscinas presentes em cidades brasileiras e, banhar-se com finalidades lúdicas, terapêuticas ou higiênicas era uma prática realizada sobretudo em águas abertas, rios, mares, lagoas ${ }^{1}$. Além disso, os conhecimentos de uma técnica racionalizada, controlada, treinada de locomover-se no meio aquático eram ainda distantes, portanto, embora sempre se tenha praticado o nado, a natação tal como a conhecemos é resultado de um processo de esportivização.

A expressão esportivização ou desportivização, empregada por Elias e Dunning (1992), refere-se ao processo de transição de práticas de divertimento e passatempos em esporte ${ }^{2}$. Os autores remontam aos Jogos Olímpicos da Antiguidade para evidenciarem as rupturas que diferenciam as práticas desse período ao que hoje se conhece por esportes. Como importantes características dos esportes modernos, ausentes em práticas anteriores, apontam: a codificação dessas práticas; maior regulamentação e uniformidade; presença de regras escritas sujeitas a revisões; horários e calendários anteriormente estabelecidos e orientações de justiça e de igualdade nas probabilidades iniciais da disputa.

Analogamente, outros autores, como Gutmann (1978) e Bourdieu (2003) reiteram e complementam essas características, sublinhando, por exemplo: i) a universalidade e especialização das regras; ii) a racionalização e quantificação da prática sob a égide da cientificação, como os treinamentos cada vez mais sistematizados e o registro dos records e marcas; iii) o secularismo, caracterização da prática como laica diferenciando o esporte moderno dos jogos da Antiguidade; iv) o aparato da burocratização, isto é, a regulamentação da prática via instituições centralizadoras e "oficiais".

A estrutura do esporte moderno, portanto, demanda uma série de dinâmicas, agentes, instituições que só seria possível em uma estrutura social capaz de conceber tais mecanismos (ELIAS; DUNNING, 1992). No cenário brasileiro, mais especificamente no contexto do litoral cearense, estruturas modernas que participam do processo de esportivização das práticas surgem e consolidam-se, principalmente, na primeira metade do século XX, a partir da década de 1920.

Este artigo tem como objetivo analisar esse processo na natação, do contexto do litoral cearense entre as décadas de 1920 e $1940^{3}$, evidenciando as manifestações nesse sentido, os agentes e as entidades envolvidas, bem como aspectos relativos à institucionalização do espaço litorâneo e à burocratização e racionalização da prática da natação no mar.

De acordo com Melo (2012), esporte e imprensa estabeleceram uma relação bem próxima na sua constituição e promoção. O esporte se propagou com auxílio da imprensa e esta se promoveu ainda mais com as notícias esportivas, que operavam dentro de uma dinâmica rotineira de informações. Nesse sentido, as fontes mobilizadas foram periódicos que circulavam na imprensa do período e exerciam função essencial na dinâmica e desenvolvimento da prática esportiva da natação; dentre eles, a revista Ceará Illustrado, que foi bastante importante na formação de uma sociabilidade praiana, e os jornais Correio do Ceará, Gazeta de Notícias e Correio do Ceará, veículo que organizava e publicitava as provas ao lado dos 
clubes (MONTENEGRO, 2020).

\section{O ESPAÇO INSTITUCIONALIZADO, UM NOVO LITORAL}

Ao tomar como objeto o processo de constituição da natação como esporte, outro aspecto imprescindível, sem o qual esse processo não seria possível, foi a formação da praia como espaço moderno. Até o início do século XX, o litoral da cidade de Fortaleza, assim como de outras cidades da costa brasileira, não se caracterizava como espaço de sociabilidade ${ }^{4}$. litoral era sobretudo associado às suas funções portuárias, pesqueiras e militares, sendo seu imaginário fortemente vinculado àquilo que Corbin (1989) denominou como território do vazio, um lugar que despertava sentimentos de medo, solidão e incivilidade, expressos nos elementos de uma natureza selvagem e inóspita, nos vagalhões, tempestades e ventanias.

A cidade de Fortaleza teria crescido de costas para o mar, edificações e casas eram erguidas com suas faixadas na direção sul da cidade, e os fundos no sentido do litoral. Pescadores já habitavam as regiões litorâneas, entretanto, para maior parte da população os mar, as areias, os coqueirais eram uma paisagem sempre presente, mas relativamente distante. No final do século XIX e início do seguinte, discursos terapêuticos vão atribuir a esse local um novo sentido, recomendado para cura e tratamento de doenças respiratórias, tuberculose, histerias. Já na década de 1920, as primeiras casas de famílias de elites, cafés, restaurantes, igrejas, clubes sociais e esportivos são construídos, dentre outras edificações que iriam tornar, progressivamente, o litoral em um lugar intrinsecamente associado à vida citadina. Ações de melhoramento urbano da região em que se inserem condições de transporte, estradas, bondes, segurança e iluminação pública, socorro a banhistas se tornam presentes, culminando inclusive com a campanha de titulação da praia nas cercanias do centro mais urbanizado da cidade $^{5}$.

A bem sucedida campanha em 1925, de oficializar o título de Praia de Iracema, novo nome que substituiria o antigo, Praia do Peixe, sintetizou a transição operada nesse espaço. De um litoral que, segundo a nota da revista Ceará Illustrado, "exhala tanta maresia e tão intenso fartum de visceras de garôpa expostas ao sol” (CEARÁ ILLUSTRADO, 1925), em direção ao novo, ao juvenil e ao moderno, sugerido pelo mesmo impresso:

\footnotetext{
Parece que, com a mudança do feio nome de Praia do Peixe, a mais formosa marinha cearense, encanto da nossa sociedade elegante, está adquirindo um desusado movimento nestes últimos dias. Ranchos de namorados felizes e sorridentes confundem os seus arrulhos com o marulho das ondas: automóveis buzinam: ouvem-se risadas e canções. (...) Influencia do novo nome... (CEARÁ ILLUSTRADO, 1925, p. 228).
}

O litoral, portanto, deixava de ser o território do vazio e passaria a fazer parte dos lugares públicos da cidade de Fortaleza, como ruas, praças e parques, um ambiente por excelência de sociabilidade, de encontros de grupos sociais distintos, do divertimento, do prazer e da contemplação. Nos finais de semana, famílias, amigos e namorados se reuniam nas areias, banhavam-se e refrescavam-se nas águas salgadas do litoral. O medo, entretanto, ainda percorria o imaginário litorâneo. Afogamentos eram recorrentes e nadar, como sugere Corbin (1989), é inicialmente uma batalha, um esforço, um combate contra a submersão, "a convicção de que é preciso antes de mais nada sobreviver justifica esta "prática violenta e ativa”. (CORBIN, 1989) 
Dessa forma, o ato de nadar era considerado uma grande façanha, verdadeiro ato de heroísmo e, sobretudo, de sobrevivência, tanto em relação a si como aos outros banhistas. Notas de afogamentos eram bastante comuns nos jornais, desde as notícias mais trágicas àquelas de amenos desfechos, narradas com lances gloriosos:

\begin{abstract}
A senhorita Lydia Lemos, figura de destaque na sociedade carioca fora arrastada pela correnteza, ficando na imminenciai de ser tragada. Todos os banhistas contemplavam a scena, mas nenhum dispunha-se a salvar a senhorita Lydia. De repente, todas as vistas voltaram-se para um jovem que nadava em direcção daquella senhorita. Todos da praia acompanhavam com grande interesse o desfecho daquelle lance de heroísmo. Com esforços inauditos o joven banhista conseguiu salvar a senhorita Lydia Ramos. (...) Os jornaes poem em destaque a bravura dos cearenses que «com o mesmo stoicismo com que afrontam a secca, afrontam as iras de Neptuno». (CORREIO DO CEARÁ, 1932, p.1).
\end{abstract}

Descrito como um ato arrojado, reflexo da valentia do povo cearense, que enfrentaria bravamente as suas duas impiedosas naturezas - a seca e o mar -, a nota atribui ao episódio conotações marcadamente de afirmação de uma identidade regional. O nado ia ganhando um status específico, ligado à sobrevivência, à intrepidez e força masculina, uma técnica de desfrute seguro e divertido do banhar-se nas águas e, progressivamente, uma técnica competitiva orientada por uma eficiência racionalizada. Em todo caso, os sentidos dessas práticas - o nado e especialmente a natação competitiva - só puderam ser concebidos dentro da estrutura de um litoral moderno, e iam sendo por ele moldados, à medida que novos elementos, agentes e dinâmicas se inseriam naquele cenário.

\title{
A CONSTITUIÇÃo DA BUROCRATIZAÇÃo ESPORTIVA: INSTITUIÇÕES, CLUBES E IMPRENSA
}

Um importante sinal de institucionalização do espaço litorâneo e das práticas que nele se instauravam foi o movimento bem-sucedido que sugeria a instalação de postos de socorros para os banhistas. Se na década de 1920, a praia passou a ser frequentada para além de seus antigos habitantes, pescadores e portuários, os afogamentos se faziam cada vez mais frequentes e a imprensa passou a sensibilizar-se com essa causa. Depois de inúmeras notas trágicas, no ano de 1929, foi instalado o posto de socorros no litoral de Fortaleza, serviço que contribuiu com a legitimação do estilo de vida litorâneo, em que preservar, cuidar, salvar significava valorizar e impulsionar o hábito dos banhos, agora merecedor dos cuidados da secretaria da polícia e segurança pública. Ao mesmo tempo, representava também uma regulamentação da prática, com indicações de locais e horários apropriados para banhos, dentre outras regulamentações (MONTENGRO, 2020).

O concurso para os socorristas consistia em uma prova de natação, tendo quatro candidatos se apresentado e identificados como "velozes e fortes nadadores" (GAZETA DE NOTÍCIAS, 1929, p.1). Com a difusão dos banhos de mar, portanto, passou a ser demandada uma profissão - os socorristas - antes inexistente, em que nadar era habilidade essencial. A relação entre as práticas dos banhos de mar, o nado e a natação iam se estreitando e aproximando, afinal de contas, nas palavras de Corbin (1989), "O temor permanente do afogamento, avivado pela convicção de que o homem não consegue flutuar nem nadar naturalmente, comanda a arte da natação.” (CORBIN, 1989, p. 88). Melo (2015) também 
sugere essa mesma relação entre a vulgarização dos banhos de mar e o desenvolvimento do hábito da natação no Rio de Janeiro, nesse momento que se pode considerar inicial da prática. Em Porto Alegre, a natação teria ainda se atrelado à prática do remo, modalidade que também se dava em meio aquático e nadar poderia tornar-se uma necessidade de segurança para seus praticantes (ASSMANN; SILVA; MAZO, 2014).

Nesse sentido, nadar ganhava múltiplas dimensões e passava a ser uma necessidade, um status, um divertimento, uma atividade terapêutica e higiênica, introduzindo-se em instituições, sobretudo nos clubes esportivos litorâneos. No final da década de 1920, o primeiro clube esportivo praiano, O Náutico, é inaugurado no litoral, contando apenas com a instalação de uma guarita. Na década de 1930, o Ideal Clube se juntaria às areias e, posteriormente, na década de 1940, o Praia Clube e o Jangada Clube também (MONTENEGRO, 2020).

Embora, possivelmente, desafios e provas já fossem realizados, os clubes esportivos foram peças-chave na reunião de nadadores, formando grupos, na realização de treinamentos e, juntamente com a imprensa, na realização de campeonatos. Ainda que a Federação Cearense de Natação, efetivamente, só tenha se formado em 1958, a burocratização ficou a cargo de outras instituições. Segundo Guttmann (1978), são instituições burocráticas esportivas aquelas responsáveis por decidir, sistematizar e anunciar as regras da modalidade de forma universal. Além disso, elas podem ter outras funções, como estabelecer relações com outros níveis de competências (por exemplo, a nível internacional, nacional ou regional) e detém o controle dos records. De acordo com o autor, as formas mais refinadas na burocratização esportiva são as Federações e Entidades com finalidade única de amparar burocraticamente as modalidades. No caso de Fortaleza, a burocratização estava a cargo, sobretudo da imprensa e dos clubes, o que evidencia que a modalidade natação encontrava-se em processo de esportivização e, por isso, não se pode considerar como esporte moderno de uma forma categórica, e sim como processo em transcurso de efetivar-se ${ }^{6}$.

No final da década de 1920 e início da década seguinte, as primeiras manifestações sistematizadas da prática da natação em formato de competição na cidade de Fortaleza se esboçavam. As provas eram realizadas em contextos festivos, como nos aniversários do clube Náutico, paralelamente a provas de outras modalidades e de jogos lúdicos. Isso ocorria, também, em formato de desafio, em que um nadador normalmente de outra cidade ou estado, desafiava os mais famosos nomes da natação local. Não havia um calendário predeterminado, tampouco um percurso, podendo as provas acontecerem nos mais diversos períodos do ano e em variadas distâncias. A organização das provas se dava de uma forma quase espontânea. A imprensa desde cedo intermediava a comunicação entre os vários agentes (competidores, clubes, estado, público), mas outros aspectos das provas eram decididos no momento de sua realização. (MONTENEGRO, 2020).

Em junho de 1931, para celebrar seu aniversário, o Náutico promoveu um evento com várias provas, dentre elas: corridas de curta e longa distância, lançamento de peso, corrida de saco, basquete, quebra-pote, cabo de guerra, salto em extensão, corrida da maçã

6 Assim como em Fortaleza, em outras cidades, esse processo de esportivização parece ter sido também tortuoso, não uniforme. Assmann, Silva e Mazzo (2014), indicam que inicialmente a burocratização da natação em Porto Alegre ficou sob tutela do remo. De forma similar deu-se no Rio de Janeiro, associando-se às práticas aquáticas (MELO, 2015). Em Fortaleza, como evidenciou Montenegro (2020), o remo não era uma prática ainda difundida quando a natação ganhou adesão dos clubes, tendo, aquela, que encontrar outras formas de entidades reguladoras. 
e provas de natação. A comemoração misturava jogos populares (como os já citados) com esportes (basquete, natação, modalidades do atletismo). As disputas da natação constavam na programação como últimas provas do evento. Frequentemente, em eventos esportivos, as últimas provas eram aquelas consideradas mais aguardadas, sendo, portanto, aquelas que geravam mais entusiasmo. Compondo o encerramento do evento, as provas de natação foram divididas em três categorias, sendo caracterizadas pelo Correio como os novíssimos, os novos e os medalhões, esboçando-se uma regulamentação, todavia ainda com tímido rigor. (CORREIO DO CEARÁ, 1931, p.5).

No final da década de 1920 e começo da década de 1930, a natação nas praias, além de ter sentido utilitário, técnica de sobrevivência e salvamento, ia estruturando-se aos poucos como prática competitiva. Alguns nomes de sportmen aparecem com certa constância, formando uma reputação em torno deles. Treinos já passavam a ser convocados pelos clubes, sobretudo pelo Náutico. A constituição do público também se formava, a imprensa convocava a comparecer nos dias de provas autoridades, associações, corporações sociais e esportivas (MONTENEGRO, 2020).

A participação das mulheres ainda era tímida, mas não inexistente; constantemente, no noticiário, destacava-se a presença delas como público. Em 1931, inclusive, verificou-se a presença de uma mulher como juíza de percurso de uma prova de natação, a "senhorita Mary Galeno de Satana” (CORREIO DO CEARÁ, 1931, p.3).

Ao longo da década de 1930, as competições iam ficando cada vez mais estruturadas, principalmente a partir de 1933, quando o Náutico, com o apoio do jornal Correio do Ceará, instituiu o Campeonato Cearense de Natação (CORREIO DO CEARÁ, 1933, p. 6). Esse evento ocorreu no final do mês de dezembro e algumas de suas caraterísticas eram ainda oscilantes, como a quantidade de participantes, o número de provas e suas respectivas distâncias. Enquanto isso, algumas provas promovidas por outros clubes e instituições continuavam acontecendo em outros períodos do ano. 

no litoral de Fortaleza (décadas de 1920-1940)

Figura 1 - EuClides, CAMPEÃo CEARENSE de NATAÇ̃̃o

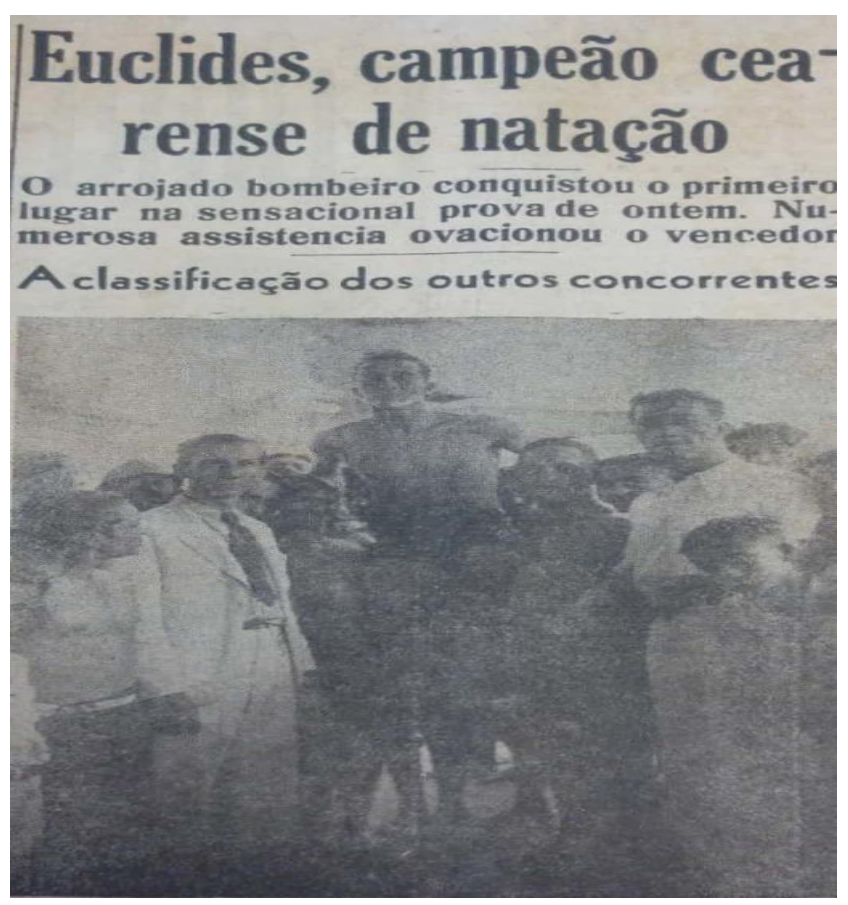

Fonte: Correio do Ceará, Fortaleza, p.7, 20/12/1937.

A imagem acima (Figura 1) retrata momentos após o final da prova do Campeonato Cearense de Natação, de 1937. O nadador vencedor, Euclides, é carregado pelo público, compondo uma cena de congregação, na qual é possível identificar outros nadadores, crianças e um grupo de espectadores, torcedores e burocratas da competição. No texto que acompanha a imagem, termos de intensa carga entusiasmada produzem a áurea festiva, esportiva, através de uma narrativa épica. O nadador, o arrojado bombeiro, e o público, caracterizado como uma numerosa assistência, se reúnem naquela sensacional prova.

Os nadadores vencedores iam se repetindo nas publicações, tornando-se personalidades. Mesmo com a dificuldade de visibilidade das provas nos mares, mesmo dentre as vigorosas braçadas, era possível identificar alguns dos sportmen por especificidades técnicas, produzindo certas individualidades dos personagens do espetáculo esportivo, como se verá a seguir: "O seu salto foi o mais belo, e ele conservou-se em primeiro lugar até a metade do percurso." (CORREIO DO CEARÁ, 1937, p.8); também em: "embora não espere colocar-se em um dos 3 primeiros lugares, com certeza irá conquistar muitos admiradores devido o belo estilo de seu nado;" (CORREIO DO CEARÁ, 1937, p.7); e, por fim, em: "tanta velocidade exige, sem duvida, grande técnica e pericia no difícil esporte das aguas” (CORREIO DO CEARÁ, 1937, p.7).

Os nadadores, na sua maioria, eram sócios dos clubes, bombeiros ou membros de instituições militares. Embora, posteriormente, membros das elites, como os nadadores da família Gentil, tenham se destacado nas provas de natação, a difusão da prática e suas provas agregaram competidores de baixa e média camadas, inclusive, pescadores, que se engajaram nas provas.

Enquanto tivessem grande intimidade com os mares, os jangadeiros não logravam 
grandes conquistas nas provas de natação. A conquista mais destacada verificada foi uma $4^{\text {a }}$ colocação de Francisco Roque de Paula da colônia de pescadores do Mucuripe (Z-2), em 1937 (CORREIO DO CEARÁ, 1937, p.7). Apesar do apoio na nota do Correio do Ceará em relação à participação dos jangadeiros, a inclusão desses grupos na lógica esportiva, de treinos, sistematizações, racionalização do tempo e espaço não era simples. A possível falta de acesso aos treinos ou a falta de tempo para dedicar-se à prática, já que a natação nesse período ainda era totalmente amadora, dificultava a inserção desses grupos sociais no cenário esportivo competitivo que vinha se desenvolvendo. Nessa mesma prova de 1937, por exemplo, dois pescadores que haviam se inscrito, perderam a largada por chegarem atrasados, sugerindo que certos códigos do esporte moderno e da vida moderna ainda não haviam sido completamente incorporados por todos os grupos.

\section{RACIONALIZAÇÃO E QUANTIFICAÇÃO: O TEMPO E O ESPAÇO NA NATAÇÃO}

A partir, principalmente, da década de 1940, a natação e suas competições seguem a orientação a qual, segundo Eric Dunning (1992), tem sido dominante no esporte: a tendência de crescente competitividade e a busca por resultados. Ainda que o profissionalismo não tenha caracterizado a prática da natação em Fortaleza, no período recortado, sendo, portanto, predominantemente amadora, havia uma crescente seriedade em torno da prática. Algo similar à estrutura da configuração esportiva, caracterizada pelo autor, parecia estar montada naquele contexto. Havia indivíduos que competiam e cooperavam em uma rivalidade mais ou menos amigável; agentes de controle, tais como árbitros, juízes de partida e chegada; espectadores, diferenciando os participantes do público. Outras características do esporte moderno, apontadas por Guttmann (1978), como secularismo, igualdade de oportunidades, especialização de regras, racionalização, a formação de uma estrutura burocrática e a quantificação também se estabeleciam.

A Prova Heroica, realizada no litoral de Fortaleza, a partir da década de 1940, tornou-se a uma das principais manifestações dessa configuração esportiva moderna no litoral cearense. Se nos anos de 1940 e 1941, a prova ainda não estava bem definida, caracterizada por duas competições de distâncias curta e longa, nos anos seguintes, passa a ser instituída como uma prova de longa distância de 5.000 metros, realizada sempre no mês de março e definitivamente denominada de Prova Heroica (MONTENEGRO, 2020). A criação de um calendário, a sazonalidade da prova, isto é, o dispositivo cronológico, como denomina Vigarello (2001), permitia a comparação de resultados, orientava a atenção para seus melhoramentos, sendo, portanto, expressão do progresso, valor dominante na modernidade.

$\mathrm{Na}$ década de 1940, as provas tiveram dezenas de competidores. A rivalidade entre os nadadores, mediada pela imprensa, era disposta em grupos, manifestando a função socializadora do esporte. O entusiasmo crescente da juventude com a natação evidenciava-se pela participação de muitas crianças e jovens, os "mosquitos", "candidatos-mirins" ou "mignon" atletas, como eram chamados pela imprensa; os jovens nadadores entre 10 e 16 anos, não só competiam nas Provas Heroicas de 5.000 metros, como conquistavam frequentemente as melhores colocações ${ }^{7}$.

7 Cf. Correio do Ceará, 10 fev. 1940, p.6; Correio do Ceará, 14 fev. 1940, p.6. 
A participação e conquistas dos pequenos nadadores eram intrigantes. Como foi possível que crianças e jovens entre 10 e 16 anos, em uma prova de resistência, se sobressaíssem em relação aos nadadores mais velhos e experientes? O que possibilitou que João Gentil Junior, para citar o exemplo mais marcante, com apenas 12 anos, vencesse nadadores jovens e adultos?

No caso específico de João Gentil Junior, o maior campeão da Heroica no período recortado, havia o fato de que o garoto pertencia a uma família da elite fortalezense e muito envolvida na cena esportiva da cidade. Seu pai, João Gentil, era banqueiro e seus irmãos mais velhos também competiam nas provas de natação, além de outras competições de atletismo, futebol, xadrez, dentre outros, demonstrando um envolvimento mais amplo e a disposição da família em relação à moda esportiva (BARROSO, 2004).

Considerando uma hipótese mais geral que englobe os outros nadadores e vencedores, para além da especificidade da família Gentil, é provável que esses jovens assimilassem com mais desenvoltura alguns aparatos da modernidade progressivamente incorporados pelo esporte moderno. Isso explicaria, por exemplo, João Gentil Junior vencer irmãos e primos mais velhos, e outros pequenos nadadores de camadas médias e baixas, e, frequentemente, destacar-se nas provas. Ao falar de aparatos da modernidade, nos referimos a alguns aspectos marcantes, como a racionalidade, e consequentemente o uso da ciência e da técnica na realização de práticas pedagógicas, competitivas, de entretenimento, incluindo o esporte.

A preparação e o esforço de João Gentil Junior eram destacados nos jornais, ressaltando seu empenho ativo nos treinamentos. Apenas sua aplicação nos treinos, todavia, não era suficiente, outros fatores se manifestavam:

Utilizando-se de um estilo perfeito, submetido a um regime alimentar apropriado, Joãozinho realizou ontem um milagre que o sagrou campeão dos 1.000 metros nado livre. Para isso, também constituiu a sua excepcional constituição física. Forte, tostado de sol, o jovem nadador é bem um símbolo da nova geração que vive em contacto com o mar (CORREIO DO CEARÁ, 1940, p.6).

O “estilo perfeito" parece referir-se à técnica do nadador; o "regime alimentar apropriado" aos cuidados e racionalidades imposta inclusive nos ambientes fora da prática; a "excepcional constituição física" ao aprimoramento das capacidades físicas, que vão impulsionar seus resultados, e, por fim, "tostado de sol”, "símbolo da nova geração que vive em contato com o mar" expressa como aquele menino e sua geração pareciam estar em sintonia com as novas disposições e com o litoral.

A partir das fotografias que seguem (Figuras 2 e 3), pode-se inferir que apesar da aparência ainda infantil, João Gentil Junior incorporava bem símbolos da voga esportiva litorânea. $\mathrm{Na}$ primeira imagem, com apenas 12 anos de idade, em contraste com o rosto infantil, destaca-se sua postura ereta, rígida, disciplinada, símbolos bastante associados às representações esportivas do período. $\mathrm{Na}$ segunda fotografia, dois anos depois, portanto com 14 anos, o jovem nadador em postura mais despojada, embora mais desenvolvido em sua composição muscular, expressa mais a leveza do ambiente litorâneo. Em ambas, a pele bronzeada e a nudez esportiva - novidades para o período - passam a ser tratadas com certa naturalidade nas páginas de jornais, demonstrando o advento de uma disposição em relação à combinação esporte-litoral. 
Figura 2 - João Gentil Junior aos 12 anos e Figura 3 - João Gentil Junior aos 14 anos

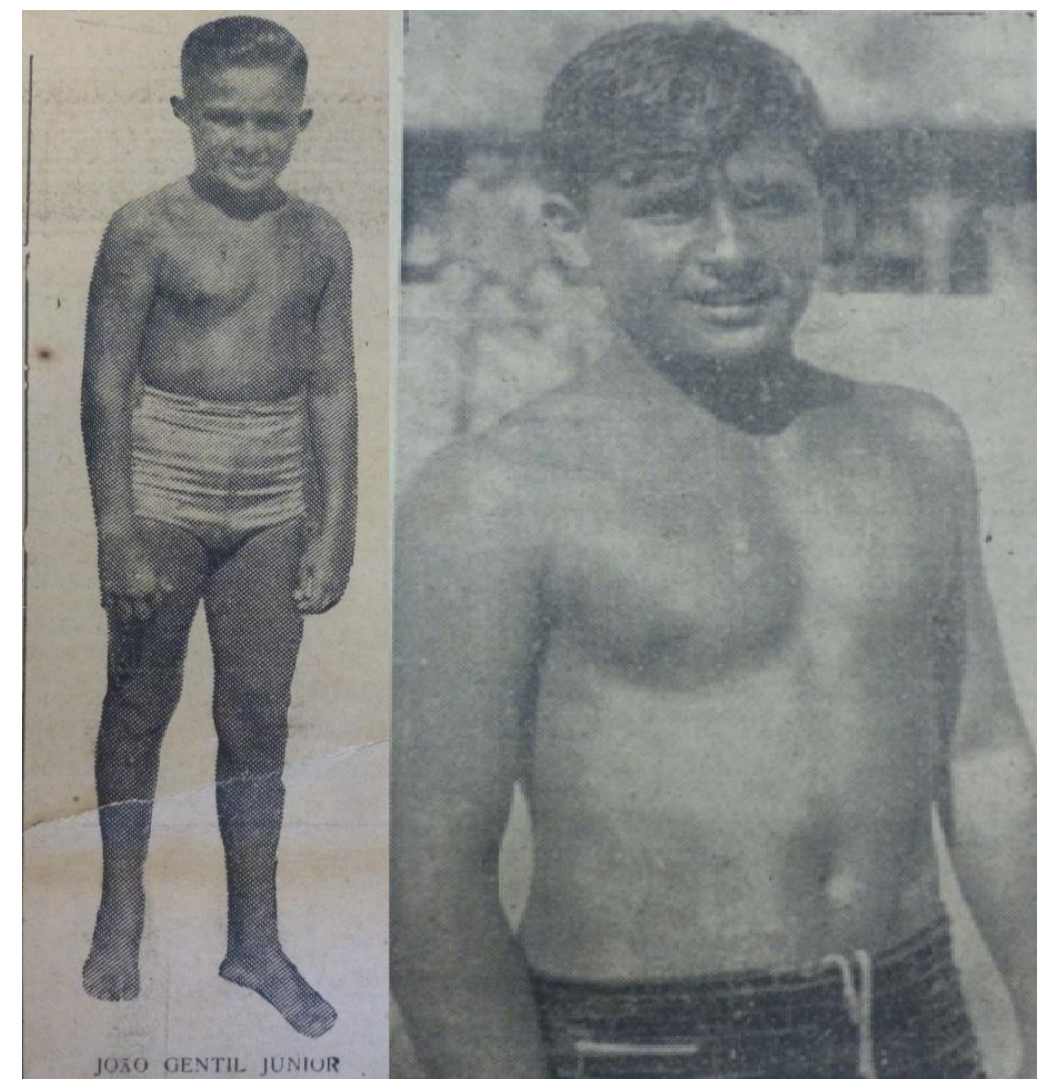

Fonte: Correio do Ceará, 17/02/1940, p.3 (Figura 2).

Fonte: Correio do Ceará, 13/07/1942, p.4 (Figura 3).

Se para os adultos do período a praia talvez fosse ainda uma novidade, para a geração de João Gentil Junior, na década de 1940, pode-se dizer que a praia já se afirmava como espaço de sociabilidade importante na cidade de Fortaleza. A própria ideia de que havia uma nova geração, que se caracterizava pela proximidade com o litoral, deixava explícito que havia mesmo uma ruptura na relação estabelecida com o ambiente praiano entre os jovens nadadores e os competidores mais velhos.

Os aparatos da modernidade invadiam as dinâmicas que envolviam a natação, especialmente as Provas Heroicas. À medida que as edições iam passando, buscava-se a implementação de mais regras e especificações nos regulamentos. Para exemplificar, há a substituição do apito pelo tiro, por ser mais audível, para indicar a largada em 1940 (CORREIO DO CEARÁ, 1940); o aumento da quantidade de juízes e organizadores em 1942 (CORREIO DO CEARÁ, 1942, p.2); a implementação da idade mínima e máxima e a padronização dos uniformes (calções e tocas), indicando inclusive as cores e o local preciso do número de inscrição na perna direita, em 1944 (CORREIO DO CEARÁ, 1944, p.3); a mudança do transporte dos atletas até a largada por terra, não mais pela água, para evitar enjoos, a partir de 1946 (CORREIO DO CEARÁ, 1946).

Cada vez mais citavam-se técnicos ou diretores de educação física, profissionais 

no litoral de Fortaleza (décadas de 1920-1940)

responsáveis pela sistematização e racionalização das práticas esportivas. A preocupação com a alimentação passava a ser reconhecida como incontornável na performance dos participantes da Heroica. Dizia-se que alguns atletas possuíam "consciência náutica", algo que parece expressar adaptação e conhecimento sobre a dinâmica da natureza marinha, o tamanho, o quebrar e a direção das ondas. A natação competitiva no mar exigia muito mais que força e resistência; a fala do nadador Balalaika é emblemática nesse sentido: "tenho confiança nos meus músculos, entretanto reconheço que não se vence a Heroica com facilidade" (CORREIO DO CEARÁ, 1942, p.3). O elemento tático, a prudência, a agressividade e o momento de manejá-los precisariam ser bem calculados, como reiterava outro nadador:

\footnotetext{
Agora tenho mais experiencia da prova. A' primeira vez que competi, não pude calcular a saída. Dei tudo no começo o que prejudicou o meu tempo. Na 2a "Prova Heroica", com os ensinamentos que aprendi, a minha tarefa será mais fácil. Não me impressionarei com o arranco inicial, poupando energias para o momento decisivo da competição (CORREIO DO CEARÁ, 1941, p.5).
}

O comércio e produtos começam a se aproximar da prática, insinuando sem, contudo, consolidar uma profissionalização. Além de medalhas, a partir da década de 1940, os melhores colocados passavam a ganhar também, como prêmios, artigos de lojas, aos quais queriam associar-se a certos símbolos que a Prova Heroica remetia. Nos jornais, a publicidade explorava também o caráter cada vez mais sistematizado e técnico da prática, relacionando-o ao seu produto. A publicidade da empresa norte-americana Gillette (Figura 4) é, inclusive, bastante pedagógica. Através de imagens e de descrições escritas, demonstra estilos de nados: peito, costas e livre.

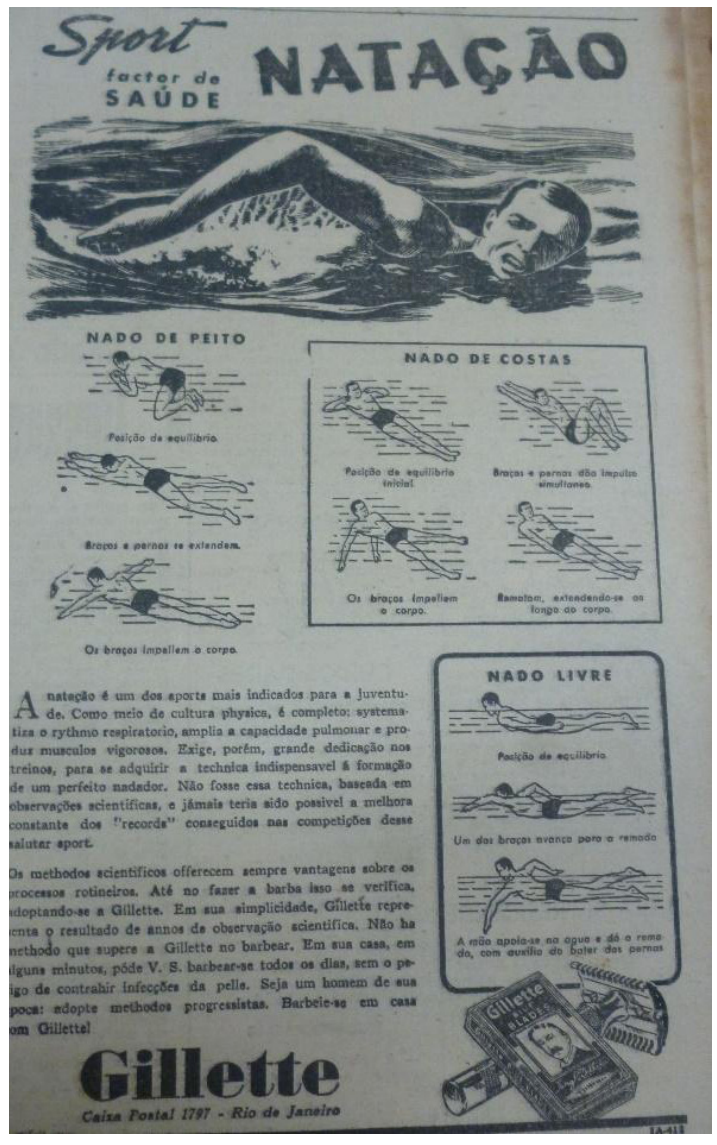

Fonte: Correio do Ceará, 23/02/1942, p.2. 
O melhor desempenho, como sugere o texto da publicidade, é consequência do desenvolvimento da técnica e de sua base científica. "Não fosse esta technica, baseada em observações scientificas, e jamais teria sido possível a melhora constante dos "records" conseguidos nas competições desse salutar sport". Da técnica da natação, transita-se até a técnica de barbear-se em casa, no discurso que tem como égide a universalidade da ciência: "Os methodos scientificos offerecem sempre vantagens sobre os processos rotineiros". O final arrebatador evidencia o que há de comum entre o ato de nadar e de barbear-se com uma lâmina em casa: "Seja um homem de sua epoca: adopte methodos progressistas" (CORREIO DO CEARÁ, 1942, p.2). Mais uma vez, a natação como prática pertencente a um novo período, como uma atividade moderna, por isso ancorada na ciência, na técnica e na racionalidade.

A publicidade da marca de relógio suíça Mido Multifort estabeleceu também uma relação direta entre seu produto e a prática da natação, tendo como elo essencial a modernidade. $\mathrm{Na}$ imagem (Figura. 5), vê-se um sujeito nadando, portando, um relógio, símbolo bastante característico da modernidade.

Figura 5 - Publicidade da Mido Multifort

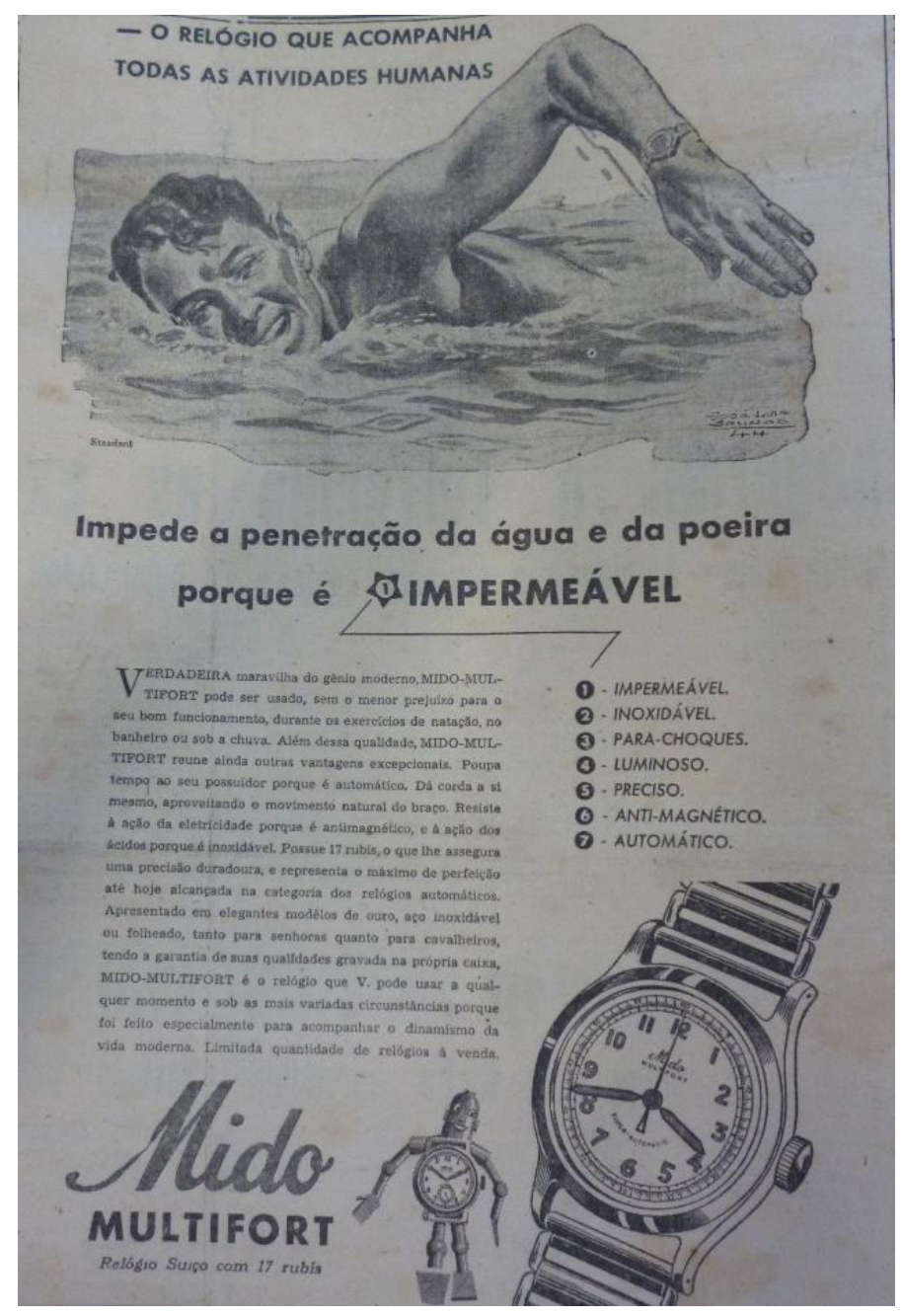

Fonte: Correio do Ceará, 22/05/1944, p.2. 
Além de "verdadeira maravilha do mundo moderno", o anúncio enaltece ainda uma qualidade mais inovadora do relógio: sua impermeabilidade, característica que possibilitava "ser usado, sem o menor prejuízo para o seu bom funcionamento, durante os exercícios de natação [...]”. O interesse na consulta do dispositivo cronológico ao nadar demonstra como o tempo havia se tornado não só um regulador absoluto dos compromissos da vida urbana mas também aquele que é capaz de medir com precisão a duração da atividade esportiva, a velocidade média do nadador e as possibilidades de superação de recordes. O relógio era, por excelência, como anuncia a publicidade, um instrumento capaz de "acompanhar o dinamismo na vida moderna” (CORREIO DO CEARÁ, 1944, p.2).

A preocupação com o tempo é um dos aspectos definidores para diferenciar a prática da natação competitiva e o simples ato de nadar. Para Vigarello (2001), o controle quase obsessivo do dispositivo temporal esportivo encontra sentido na regularidade das competições. $\mathrm{O}$ tempo é um mecanismo de comparação. A ascensão da preocupação com sua medição, a ideia de tempo vigiado e confrontado foram determinantes nas "Disposições técnicas tomadas para ganhar segundos" (p.239), portanto, decisivas no desenvolvimento de uma sensibilidade, bastante presente no esporte moderno, no aperfeiçoamento constante e no progresso ${ }^{8}$.

Havia um desejo declarado, nas Provas Heroicas da década de 1940, de que as marcas dos anos anteriores fossem superadas na edição vigente. Os jornais, ao divulgarem os resultados, além de estabelecerem comparações entre os nadadores, o faziam também entre os tempos de edições anteriores, dando a ilusão de que uma competição com o passado seja possível, como analisou Guttmann $(1978)^{9}$; quando conseguiam, enaltecia-se o senso de desenvolvimento esportivo e de progresso, como no seguinte trecho: “Todos os atletas classificados, cuja duração de percurso foi apurada, sobrepujaram a marca passada de João Gentil, credenciando desta maneira a IV Heroica superior a III.” (CORREIO DO CEARÁ, 1943, p.4).

Contudo, em alguns casos, principalmente quando o tempo estava chuvoso e as ondas eram mais revoltas, os nadadores não conseguiam superar as marcas anteriores. A regularidade e o controle rigoroso do tempo, inevitavelmente, iriam exigir também a estabilidade do espaço; orientação que se seguiu nos anos seguintes, principalmente no final da década de 1940 e durante 1950, com a construção de piscinas nos clubes, produzindo um novo formato para essa prática, ainda mais controlada, rígida e estável. As piscinas não iriam decretar o fim das Provas Heroicas nem de outras competições no mar. No entanto, é a partir desse marco que a natação se subdivide, especializando provas, sobretudo de velocidade nas piscinas, com uma variedade de estilos de nado e, por outro lado, as grandes provas de resistência nos rios e mares, as quais, hoje, convencionou-se chamar de natação em águas abertas.

\section{CONSIDERAÇõES FINAIS}

Parte do processo de esportivização da natação em Fortaleza deu-se entre as décadas de 1920 a 1940. Se antes desse período nadar era uma prática voltada à sobrevivência, à diversão,

8 Medeiros (2021) , em pesquisa sobre competições aquáticas em que se incluem natação e o remo discute de forma bastante acurada a importância do dispositivo temporal e seu controle cada vez maior nas competições, nos rios de São Paulo.

9 No original: "What is a record in our modern sense? It is the marvelous abstraction that permits competition not only among those gathered together on the field of sport but also among them and others distant in time and space" (GUTTMANN, 1978, p.51-52). 
à terapêutica, nesse intervalo de tempo, outros sentidos foram agregando-se sem, contudo, que os anteriores deixassem de existir.

No começo do século XX, a modernização do litoral, evidenciada pela instalação de estabelecimentos, residências, instituições, obras de transporte, converteu progressivamente esse espaço em parte essencial da sociabilidade urbana. A natação amparou-se em diversas dessas mudanças para sustentar novas dinâmicas que a tornaram competitiva, treinável, racionalizada, portanto, esportivizada.

Nesse processo, destaca-se o papel dos clubes sociais e esportivos como importantes meios de captação e de reunião de nadadores, bem como no movimento de racionalização da prática, caracterizada pelo controle de tempo e espaço e o desenvolvimento de uma ideia de treinamento. Na ausência de federação da modalidade no período, juntamente com os clubes esportivos, a imprensa exercia função burocrática, sendo responsável pela organização dos eventos e campeonatos, desde a inscrição, passando pela publicidade até a premiação.

De forma gradual, com o passar dos anos, as provas de natação no litoral de Fortaleza tornavam-se cada vez mais esportivizadas, isto é, mais amparadas pelas instituições, mais regulamentadas e específicas, mais quantificadas, enfim, operando dentro da lógica do esporte moderno caracterizada pelos autores Elias (1992) e Guttmann (1972). Esse processo, entretanto, não se esgota no período recortado. As competições de natação no litoral cearense ainda deixavam a desejar, devido, sobretudo, às condições irregulares dos mares, no sentido da racionalização e progressão tão representativas no esporte moderno. Esse cenário seria tensionado com a inicial aparição de piscinas nos clubes e, consequentemente, com o exercício de outras formas de natação competitiva, tornando ainda mais plurais as possibilidades dessa prática. 


\section{REFERÊNCIAS BIBLIOGRÁFICAS}

ARAÚJO, Rita de Cássia Barbosa de. As praias e os dias: história social das praias do Recife e de Olinda. Recife, PE: Prefeitura do Recife, Secretaria de Cultura, Fundação de Cultura Cidade do Recife, 2007.

ASSMANN, Alice; SILVA, Carolina; MAZO, Janice. A natação em piscinas nos clubes da cidade de Porto Alegre (décadas de1930 e 1940). Kinesis, v. 31, p. 05-21, 2014.

BARROSO, Francisco de Andrade. O Benfica de ontem e de hoje. Fortaleza: LCR, 2004.

BOURDIEU, Pierre. Como se pode ser desportista? Questões de sociologia. Lisboa: Fim de Século- Edições, Sociedade Unipessoal Ltda, 2003, p.181-203.

CORBIN, Alain. História dos tempos livres: o advento do lazer. Coautoria de Julia Csergo. Lisboa: Teorema, 2001. cap.6, p.229-262.

CORBIN, Alain. O território do vazio: a praia e o imaginário ocidental. São Paulo, SP: Companhia das Letras, 1989.

DANTAS, Eustógio W. C. Maritimidade nos trópicos: por uma geografia do litoral. 2a Ed. Fortaleza: Edições UFC, 2010.

DEVIDE, Fabiano; VOTRE, Sebastião. Primórdios da natação competitiva feminina: do 'páreo elegância' aos Jogos Olímpicos de Los Angeles. Revista Brasileira de Ciências do Esporte, v. 34, p. 217-233, 2012.

ELIAS, Nobert; DUNNING, Eric. A busca da excitação. Lisboa: Difel, 1992. cap. VII, p.299325

ELIAS, Norbert. O processo civilizador. Revisão de Renato Janine Ribeiro. Rio de Janeiro, RJ: Jorge Zahar, 1994.

FREITAS, Gustavo. Práticas de divertimento no Cassino/RS em meados do século XX: a produção de um outro espaço no encontro com os infames. 141p. Tese (doutorado) Universidade Federal do Rio Grande, Programa de Pós-Graduação em Educação em Ciências: Química da Vida e Saúde. 2014.

GUTTMAN, Allen. From ritual to record: the nature of modern sports. New York, NY: Columbia University Press, 1978.

HOLLANDA, Bernardo; Melo, Victor (org.). O Esporte na imprensa e a imprensa esportiva no Brasil. Rio de Janeiro, RJ: 7Letras: FAPERJ, 2012.

MEDEIROS, Daniele Cristina Carqueijeiro de. Entre esportes, divertimentos e competições: a cultura física nos rios Tietê e Pinheiros (São Paulo, 1899-1949). 2021. 264p. Tese (doutorado) Universidade Estadual de Campinas, Faculdade de Educação, Campinas, SP. 2021.

MELO, Victor Andrade de. Enfrentando os desafios do mar: a natação no Rio de Janeiro do século XIX (anos 1850-1890). Revista de História (São Paulo), n.172, p.299-334, jan-jun, 2015.

MONTENEGRO, Nara Romero. A cultura física e suas manifestações no litoral de Fortaleza (1925-1946): novos modos de se educar e de se divertir.(160 p.) Dissertação (mestrado) Universidade Estadual de Campinas, Faculdade de Educação, Campinas, SP, 2020.

MORAES, Claudia. A educação do corpo à beira-mar: esporte e modernidade na ilha de Santa Catarina (1857-1932). Tese (doutorado) - Universidade Federal de Santa Catarina, Centro 
de Ciências da Educação, Programa de Pós-Graduação em Educação, Florianópolis, 2017

O’DONNELL, Julia. A invenção de Copacabana: culturas urbanas e estilos de vida no Rio de Janeiro (1840-1940). Rio de Janeiro: Zahar, 2013.

SCHOSSLER, Joana Carolina. História do veraneio no Rio Grande do Sul. Jundiaí, SP: Paco, 2013.

SCHRAMM, Solange Maria de Oliveira. Território livre de Iracema: só o nome ficou?.

Memórias coletivas e a produção do Espaço na Praia de Iracema. 2001. 176f. Dissertação (mestrado) - Universidade Federal do Ceará, Centro de Humanidades, Fortaleza, 2001.

SOARES, Carmen Lúcia. Uma educação pela natureza: a vida ao ar livre, o corpo e a ordem urbana. Campinas: Autores Associados, 2016.p.205-238. 